\title{
OBSERVATIONS WITH WIDE-BAND GRAVITATIONAL RADIATION DETECTORS*
}

\author{
R. W. P. DREVER, J. HOUGH, R. BLAND, and G. W. LESSNOFF \\ Dept. of Natural Philosophy, University of Glasgow, Scotland, U.K.
}

\begin{abstract}
The principles and operation of wide-band gravitational radiation detectors are described. In 7 months of coincidence observations, one signal which fulfills requirements set for a gravitational wave event was recorded, and details are presented. The experiment sets an upper limit to millisecond pulses of gravitational radiation of $0.9 \pm 2.1$ per month at a $25 \%$ threshold of $0.3 \mathrm{kT}$ in $300 \mathrm{kG}$ bars, which appears inconsistent with the flux implied by Weber's 1970 results if these are due to such pulses.
\end{abstract}

* This work has been submitted for publication in Nature. Part of it will be published in Proceedings of the Symposium on Gratitational Waves and Radiation, Paris, June 18-22, 1973. (To appear as C.N.R.S. Report No. 220.) 